\title{
Indian Conjuring
}

\author{
By Lieut.-Colonel R. H. Elliot, late I.M.S.
}

$\mathrm{T}$ HERE is a widespread belief among British people who have not visited the East that India is the 'home of mystery'. I have come across not a few men and women in high and responsible positions who share this erroneous idea. In 'the dim red dawn of man' every strange natural phenomenon was ascribed to the supernatural. Slowly but surely knowledge grew, explanations displaced superstition, and reason, greatly daring, trespassed more and more on the once undisputed domains of the gods, with the result that one mystery after another was resolved by the onward march of common sense. The area of the 'supernormal' has steadily shrunk, and is daily still shrinking. The discovery of facts has always preceded the explanation of their causal origin. There are many things which still puzzle us; we have no valid explanation for them; we freely admit our ignorance and wait for the advance of the tide of knowledge which we believe will sweep on irresistible and ever progressive, washing out as it goes the ripples on the sands of ignorance.

In the early days of our colonization of the East, men watched with wonder the fearlessness with which the Indian snake-man handled his dangerous pets. They saw 'the mango trick', the disappearance of the girl from the basket which was stabbed in every direction by a sword, and the speedy return of the young woman unharmed at the bidding of her master. Then there was the duck, which bobbed at every word of command, answering by the number of its bobs the questions of the performer, and so on. At first the European looked on at these and at a number of other wonders of the same kind, and following the line of least resistance, ascribed the phenomena to mysterious causes which were beyond finding out. As time went on, men who had been imbued with an interest in conjuring before they left 'home', started to study the 'tricks' which had obtained so wide a fame. To their surprise they soon found that conjuring as practised in the East was dependent on the very same factors which governed the art they had learnt at home.

The veil of mystery which had shrouded the Orient was little by little lifted to expose trickery, misdirection and humbug. There was, however, one great difference. In the West, the performer made no bones about the fact that he was deceiving his audience, whilst the Eastern always claimed supernatural powers for himself. Around all his doings he threw a veil of mystery; he was and is a past-master in the art of humbugging his clientele; he never allowed one of his tricks to be taken as a laughing matter; his whole technique was that of the 'priest of mystery'; the matter was a very serious one, no matter how trivial the 'experiment'- he would not have it called a trick for anything-might be.

Step by step our people unravelled the mysteries, dragged them into light and saw them in all their pitiful fraudulence, until it became clear that the fact that a man has a brown, black or yellow skin, and lives in far-away parts of the earth little known to the majority of us, gives him no claim whatever to mystery. Man is man wherever you may find him; his powers are as limited in China as in Chiswick, in Tibet as in Tooting. Nearly 2000 years ago Tacitus coined the phrase "omne ignotum pro magnifico", a dictum which has pricked the bubble of many a mystery. The wonderful 'mango trick' is based on such barefaced deception that were a performer to present it before the "Magic Circle" at one of our monthly meetings, he would be laughed off the stage. The marvellous nodding duck is dependent on a principle so elementary that my grandson of eleven years of age-a budding magician-would hesitate to use it, unless it were combined with other methods which would help to conceal the fraud. The earthenware medallion, on which the Christian is invited to inscribe the symbol of his faith, with the result that though the disk is ground to powder beneath his foot, the cross is found imprinted on his hand, suffices at first to astonish the subject of the experiment, until he has had time-provided he has the intellect--to solve the very simple device which led him astray. The wonderful seer who reads your fortune in the sand tells you things which seem supernatural in their source, unless you realize that your personal servant has been impanelled to help deceive you. Your conversation has been listened to, your letters read and the information so gained has been handed to the 'holy man' in exchange for the receipt of a small coin of the realm. One might go on with a number of other 'tricks'; and please note that 'tricks' they are, nothing more and nothing less.

At the present time, most sensible people know all about the majority of these wonders of the East, but two remain to puzzle and disconcert a number of our fellow-countrymen, even including some who have spent the best years of their lives 
in the East. I refer to the 'Rope Trick' and to 'Levitation'. The Occult Committee of the Magic Circle, a Committee of which I have the honour to be chairman, spent a great deal of time sifting the evidence in favour of the former performance, for which supernatural origin has been so freely claimed. At a meeting held in London on April 30, 1934, with the late Lord Ampthill, a former acting-Viceroy of India, in the chair, we submitted a résumé of the evidence which we had collected. Lord Ampthill said that during his viceroyalty he had tried hard to see the 'rope trick', but in vain. Similar evidence had been sent us by letter from the late Viceroy, Lord Irwin. Lord Meston, the Right Rev. the Bishop Welldon (formerly Metropolitan of India), Sir Michael O'Dwyer and others supported Lord Ampthill, whilst the last-named mentioned that he had asked the Nizam of Hyderabad if he could help him, but though probably the most powerful prince in India, His Highness could not do so. Those who are interested in the subject will find it fully discussed in the second and third chapters of my book "The Myth of the Mystic East" (Blackwood).

No better illustration could be given of the way in which evidence in favour of this trick has been adduced than the statement made by a correspondent in the Western Morning News of November 29, 1934, who wrote as follows: "According to a correspondent, the Indian Rope Trick was performed before several hundreds of men who landed in India from Her Majesty's troopship Malabar. It was performed several times a day, not in bad light or when it was dark, but in the full light of the Indian sun. The Duke of Connaught watched the performance sitting on his horse and seemed highly interested." This story, so circumstantially told, seemed as if it must be true, but I had the privilege of being able to submit it to His Royal Highness, through the kindness of a member of his staff, and this is the reply I received : "With reference to the enclosed letter from Colonel Elliot, I sent it to the Duke. Quoting from his letter, he says : 'After these many years I am unable to remember small events of that time, but I have no recollection of ever having seen the rope trick during my service in India, or even heard of it." " It is impossible to believe that His Royal Highness would ever have forgotten such a supernormal happening. I am greatly in His Royal Highness's debt for so graciously answering my question. It serves to show the way in which the names of our Royal Family are used behind their backs, in a manner which it is very difficult for them to resent. Their outstanding popularity carries great weight with the public, and leads many people to accept stories as ridiculous as this.
There are two recent incidents which deserve a brief mention. The first of these was the so-called 'Cheltenham Rope Trick'. A gentleman who styled himself "Professor" declared that he had discovered how to perform the 'Indian Rope Trick', and had actually done it before a meeting of a society of conjurers. This statement was widely advertised in the Press, and a local photographer stated that he had photographed a girl "as she reached the top of the rope-but when he developed the film, to his amazement, no trace of the girl was to be seen. The rope was bare". I took some trouble to run this story to earth, and was in communication with officials of the society, and with a gentleman of undoubted honesty who was present at the meeting in question. What did it all amount to? It was just a joke at the expense of the local press-man. A wire had been suspended between the tops of two tall trees, a rope was hung from this, care being taken so to arrange the light that the wire was not visible, and the dupe was told that just before his arrival a girl had ascended the rope and disappeared. The members of the society were much annoyed at the publicity that this trick had attracted and were very unwilling that more publicity should be given to it than they could help. I had to fall in with their wishes. Measures had been taken to prevent any further absurd claims being made. All the same, from time to time notices appeared in the Press, dealing with this incident as if it were worthy of credence instead of being the joke--perhaps not in the best of taste- that it was. My son sent me a copy of it from an Indian paper in which it was taken seriously.

There remains the 'Plymouth Demonstration of the Rope Trick' by Karachi, who, by the way, in private life was a Mr. Arthur Darby. There can be no doubt that a number of honest witnesses, who, however, had not had the benefit of a training in conjuring, were taken in by Karachi, who was simply performing a conjuring trick, which some people have thought very clever, but which to those of us who have studied conjuring was a very cheap form of deception. Mr. Harry Price exposed it in the Listener (January 16, 1935), and there was a lot of correspondence on the subject, much of which called to mind Carlyle's bitter dictum on the subject of the intelligence of the population of Great Britain.

The other much disputed topic is that of the power of Oriental fakirs to practise 'levitation'. Many years ago, Messrs. Maskelyne put on a show in which a girl was apparently suspended in midair lying horizontally. Hoops were passed round her in various directions to show that there were no mechanical aids to her flotation. It need 
scarcely be said that it was simply a clever piece of illusion. The Eastern magician presents a similar trick, and much has been made of it in a recent issue of the Illustrated London News. Many Europeans have seen this clever performance, but some at least of those who have described it have not been very skilled observers. What actually occurs is substantially as follows: The girl lies on the ground and is covered up; a sort of tent is built round her; then under cover of it she is raised up ; the tent is gradually taken away bit by bit, until she is seen lying suspended as it were above the ground, but with some of her coverings dropping down to the ground near her head end in what appears a very innocent way. The spectator is not allowed to go up and examine this drapery or he would find out that it conceals an iron post driven into the ground. Were he allowed further license, he would soon discover the secret of the trick, which indeed is very similar to the device used by Maskelyne long ago. An Indian civilian who occupied a high position in the country recently wrote to me describing how he had this trick performed in his compound at a garden-party. Among his guests was a wellknown bishop who was greatly troubled by what he took for a satanic manifestation, until the Commissioner asked him how the man described his performance. "As a trick," replied the bishop. "Well, if he only claimed for it that it was a trick you may be sure it was nothing more. He would certainly not err on the side of modesty in his claims."
In reading of, or in listening to descriptions of this trick as given by men who have not had a training in conjuring-the art of suggestion and misdirection-I would urge readers to be very sceptical. They are often misled to think that events happened far differently from what they actually did. Time after time I have heard people describe what they thought they saw, and knowing how the trick was done I have been astonished that they can have been so hopelessly misled as to the real facts. The success of any and every conjuring show depends on this factor of deception.

We read and hear wonderful descriptions of yogis buried alive and being none the worse for it. In those cases in which expert conjurers have witnessed such experiments, it has been quite clear that the actual conditions were not those claimed by the performer. By means well known to expert magicians-I use the term without prejudice-the suffocation of the subject was easily avoided, though doubtless the experience was sufficiently unpleasant. I know the wonderful claims that have been put forward, but I have so often had the opportunity of checking such claims by careful observation and discovering their worthlessness that I am very far from being convinced.

Once again I would urge readers to look always for a natural explanation of any phenomenon, and when one is not forthcoming, to await the advent of more knowledge, confident that a normal and not a supernormal explanation is always forthcoming, provided that we have the requisite knowledge.

\section{American Early Tertiary Mammals}

\section{$\mathrm{T}$} HE White River formation of western North America contains numerous well-preserved fossil skeletons of mammals which date back to Oligocene times when some present-day families were beginning to flourish. The rocks seem to have been formed by floods on a very extensive plain, where the carcases of animals which lived under varied conditions were washed together repeatedly during a long period. The fossils therefore give a very good idea of the mammals which were living on the North American continent during a particularly interesting episode in the evolution of mammalian life. They have already been described in numerous scattered works and papers, but modern methods of collecting have provided so many more satisfactory specimens that there is now an opportunity for a comprehensive review of the whole fauna.
Such a review is being undertaken by Prof. W. B. Scott and Prof. G. L. Jepsen, of Princeton University, who have just published the first part of their work dealing with the Insectivora and Carnivora*. None of the Insectivora has the vacuities in the bony palate and the incompleteness of the zygomatic arches which characterize some existing Insectivora, so that these must be regarded as degenerate, not primitive features. Of the Creodonta or earliest Carnivora, only some Hyænodontidæ survive in the American Oligocene, but very fine skeletons have been obtained from the White River formation. The authors are as much puzzled as previous investigators to explain the use of the long passage above the palate of

\footnotetext{
* The Mammalian Fauna of the White River Oligocene. Part I. Insectivora and Carnivora. Trans. Amer. Phil. Soc., N.S., 28, Part 1. Pp. ii $+153+22$ pl. (Philadelphia : American Philosophical Society ; London: Oxford University Press, 1936.)
} 